\title{
Reputational Economies of Scale
}

Miguel F.P. de Figueiredo

Daniel Klerman

Follow this and additional works at: https://opencommons.uconn.edu/law_papers

Part of the Law and Economics Commons

\section{Recommended Citation}

de Figueiredo, Miguel F.P. and Klerman, Daniel, "Reputational Economies of Scale" (2020). Faculty Articles and Papers. 474.

https://opencommons.uconn.edu/law_papers/474 


\title{
Reputational Economies of Scale
}

Daniel Klerman

\author{
Miguel F. P. de Figueiredo*
}

\begin{abstract}
For many years, most scholars have assumed that the strength of reputational incentives is positively correlated with firm size. Firms that sell more products or services were thought more likely to be trustworthy than those that sell less because larger firms have more to lose if consumers decide they have behaved badly. That assumption has been called into question by recent work that shows that, under the standard infinitely repeated game model of reputation, reputational economies of scale will occur only under special conditions, such as monopoly, because larger firms not only have more to lose from behaving badly, but also more to gain. This article shows that reputational economies of scale exist even when there is competition and without other special conditions, if the probability that low quality is detected is positively correlated with the quantity of the good or service sold. It also shows that reputational economies of scale exist, under some circumstances, in a finite-horizon model of reputation. Reputational economies of scale help explain why law and accounting firms can act as gatekeepers, why mass market products are more likely to be safe, why firms are less likely to exploit one-sided contracts than consumers, and why manufacturers market new products under the umbrella of established trademarks.
\end{abstract}

* Klerman is Edward G. Lewis Professor of Law \& History, USC Law School, dklerman@law.usc.edu. de Figueiredo is Associate Professor of Law, University of Connecticut School of Law, mdefig@uconn.edu. The authors thank Heski Bar-Isaac, John de Figueiredo, Jonah Gelbach, Ed Iacobucci, Alex Lee, Bentley MacLeod, Eric Rasmusen, Steven Shavell, James Spindler, Megan Stevenson, Steven Tadelis, Joshua Teitelbaum, and participants at the American Law \& Economics Association 2012 annual meeting and Law \& Economics Section of the American Association of Law Schools 2018 annual meeting for their comments and suggestions. The authors also thank Timothy Hughes and Jeffrey Zhao for their help on Section 4 and Appendix A. Finally, the authors thank Rui de Figueiredo, Jr., and Ben Johnson for invaluable technical help on the paper. 


\section{Introduction}

For many years, most scholars have assumed that the strength of reputational incentives is positively correlated with firm size. The conventional wisdom was that firms that sell more products or services are more likely to be trustworthy than those that sell less because larger firms have more to lose if consumers decide they have behaved badly. This assumption helps explain why law and accounting firms can act as gatekeepers, why mass market products are more likely to be safe, why firms are less likely to exploit one-sided contracts than consumers, and why manufacturers market new products under the umbrella of established trademarks (Kraakman 1984 p. 891, Coffee 2006 p. 136, S. Choi 1998, Barnett 2012, Polinsky \& Shavell 2010 p. 1491, Bebchuk \& Posner 2006 p. 832, but see Macey 2013 Chapters 6 and 7).

Nevertheless, articles by Eric Rasmusen (2016) and Edward Iacobucci (2012) call into question the assumption of reputational economies of scale. They assert that, under the infinitely repeated game model of reputational enforcement, there is no advantage to firms that sell more. While firms that sell greater quantities have more to lose if they misbehave, they also have more to gain from misbehaving, and these two effects offset each other precisely. Instead, Rasmusen and Iacobucci assert that there are reputational economies of scale only under special circumstances, such as monopoly. Rasmusen and Iacobucci's work is consistent with prior work that shows reputational economies of scale exist because those prior articles assume an infinitehorizon model in which sellers are able to price monopolistically (Rob \& Fishman 2005, Cai \& Obara 2009, J. Choi 1998, Wernerfelt, 1988). ${ }^{1}$

This article argues that reputational economies of scale exist under the infinitely repeated game model of reputation, even when there is competition and without other special conditions. The infinitely repeated game reputation model requires only minor adjustment in order to generate reputational economies of scale. The only modification necessary is to assume that low quality is detected with probability less than one and that the probability of detection is positively correlated with the quantity sold. This assumption is valid for nearly all situations to which reputational enforcement is usually applied. For example, if a manufacturer skimps on the safety of its products, the probability that any one product will cause an accident is likely to be less than one. Nevertheless, if the manufacturer sells many products, it is quite likely that there will be accidents. As it sells more low-quality products, there will be more accidents and more bad publicity, and consumers are more likely to choose to buy other products. Similarly, if an accounting firm is not rigorous in an audit of a single company in a single year, the probability

\footnotetext{
${ }^{1}$ Rogerson (1983) shows that higher quality firms tend to have more customers in a model with competition, although he assumes that firms "make a once-and-for-all quality choice upon entering the market" and therefore do not face that moral hazard problem (temptation to shirk on quality) that characterizes most of the literature. Helpful surveys on reputation include Bar-Isaac \& Tadelis 2008, MacLeod 2007, Mailath \& Samuelson 2006.
} 
that its lack of rigor will become known is less than one. Nevertheless, if an accounting firm is consistently sloppy in its audits of many companies, the low quality of its audits will eventually damage its reputation.

Rasmusen and Iacobucci's argument against reputational economies of scale applies with almost equal force to finite-horizon models of reputation, such as the models developed by Kreps and Wilson (1982) and Milgrom and Roberts (1982). In fact, even with monopoly, there are no reputational economies of scale in simple-finite horizon models. Nevertheless, the same modification - that the probability of detection is positively correlated with quantity sold - is also sufficient to generate reputational economies of scale in a finite horizon model of reputation when the firm sells high quality in all but the last period.

Section 2 briefly sets out the point made by Rasmusen and Iacobucci that, under the basic infinitely repeated game model of reputation, there are no reputational economies of scale. Section 3 modifies the basic model by assuming that the probability of detection is less than one. It shows that the minimum quality-assuring price decreases with the volume of sales. Section 4 analyzes the umbrella branding context and shows that a firm that uses the same trademark for two products can credibly commit to high quality at a lower price. Section 5 analyzes reputational economies of scale under a finite horizon model with two types. Section 6 discusses caveats, extensions, and possible reputational diseconomies of scale, and Section 7 concludes.

2. Lack of Economies of Scale in the Basic Infinite-Horizon Model

This section generally follows Rasmusen's (2016) formalization of Klein and Leffler's 1981 article, with modifications noted in the footnotes. ${ }^{2}$ This model has two features that make it especially appropriate for the analysis of reputational economies of scale: there are no fixed costs, and marginal costs are constant. By eliminating two non-reputation-related factors that create economies of scale, this model allows one to focus on the scale effects of reputation. In order to examine the effects of scale, we will initially assume that firm size is exogenous and then show whether larger firms can credibly commit to sell high quality at lower prices.

If the incentive-compatibility constraint for larger firms is consistent with selling higher quality a lower price than the incentive-compatibility constraint for smaller firms, we will say that there are reputational economies of scale. This is consistent with Rasmusen (2016), which focuses on whether high quality is "viable" at lower prices for multi-product firms. We will also show that, when there are reputational economies of scale, the lower price is part of the most plausible grim-trigger equilibrium, and that if both large and small firms could enter the market, the most plausible equilibrium would involve the larger firms making all the high-quality sales and smaller firms exiting the market.

${ }^{2}$ Where this section differs, it mostly takes features from closely related models in Rasmusen (1989) and (2007). 
Because infinitely repeated games have many equilibria, the propositions in the paper will focus on the incentive-compatibility constraint. Like Rasmusen (2016), this paper focuses on grim-trigger equilibria, because they are more tractable and are relatively common in a number of settings. Other equilibrium strategies are, of course, possible, but they are more complicated and are likely to result in similar properties with respect to scale.

In each period, there are $N>1$ potential firms that may participate in the market by selling at least one unit of the relevant good. ${ }^{3}$ A firm that chooses not to participate gets a payoff of zero. Each period, each firm can choose to make products of high or low quality. Quality cannot be observed by consumers at the time of purchase. It costs a firm $c>0$, paid at the end of the relevant period, to produce a unit of the high quality good; it costs zero to produce the low quality good. ${ }^{4}$ Each period, each firm chooses its price $p$. There is a large number of consumers, $Q>N$, each of whom is willing to pay up to $v$ for one unit of the high-quality good, and is willing to pay zero for the low-quality good. ${ }^{5}$ Each period, consumers choose to purchase at most one unit of the good and which firm to buy it from. The amount consumers buy, in aggregate, in each period from firm $i$ is denoted $q_{i}$, and firms receive the payment at the end of the period. As noted in the first paragraph of this section, $q_{i}$ is treated as exogenous, at least initially. ${ }^{6}$ After purchasing the good, each consumer learns the quality of the good she purchased and can use that knowledge to determine which firm to purchase from in the next period. Knowledge is shared among all consumers. The discount rate is $r>0$. The game repeats infinitely. Since this is an infinitely repeated game, there are many equilibria. The equilibria of interest, however, are those that sustain the production of high-quality goods. The exposition below is confined to ascertaining the conditions for such equilibria.

We focus on the incentive-compatibility constraint. That is, under what conditions is it rational for a firm to sell high-quality rather than low-quality? Because, as discussed below, the equilibrium of interest involves a grim-trigger strategy, we will focus on 2 alternatives: (1) producing $q_{i}$ units of high-quality products in every period and receiving a price, $p$, and (2)

${ }^{3}$ Rasmusen (2016) does not specify the number firms when analyzing a "competitive industry," but merely states that "more than one firm can offer each product and they engage in price competition." (p. 266). For the analysis here, where quantity is a key variable of interest, it is helpful to specify the number of firms, as in Rasmusen $(1989,2007)$.

${ }^{4}$ Rasmusen (2016) assumes that low quality costs $c$ to produce and that high quality costs $(1+\gamma) c$ to produce. Without loss of generality, we normalize the cost of low quality to zero and focus only on the additional cost of producing high quality. This makes the math simpler and follows Rasmusen (1989, 2007).

${ }^{5}$ Rasmusen (2016) assumes a "max of size $x$ of infinitesimal consumers.... willing to pay up to $v$ for low quality or $(1+\theta) v$ for high quality..." (p. 263). For the analysis here, where quantity is a key variable of interest, it is helpful to have a have a whole number of consumers. In addition, like cost discussed in the prior footnote, without loss of generality, we normalize consumer's valuation of low quality to zero to simplify the math.

${ }^{6}$ As discussed in greater detail in footnote 7 , this means that, if all firms sell the same number of high-quality goods and all consumers purchase high quality, then $N=\frac{Q}{q i}$. 
producing $q_{i}$ units of low quality in the first period, getting the high price in the first period, and then receiving zero profits in every other period:

$$
\frac{q_{i}(p-c)}{r} \geq \frac{q_{i} p}{1+r}
$$

A little algebra shows that the lowest price, $p^{*}$, consistent with the incentive compatibility constraint is:

$$
p^{*}=(1+r) c
$$

$p^{*}$ is the quality-guaranteeing price. It is the minimum price that gives a firm an incentive to sell high-quality goods. Note that the quality-assuring price does not vary with the quantity sold by each firm, $q_{i}$. The reason, as pointed out by Iacobucci (2012), is that larger firms both have more to lose in the long run by forfeiting the profits generated by high-quality products and have more to gain in the short run by selling low-quality, cheaper products, at the high-quality price. These two effects cancel each other out completely in the basic model, so large firms and small firms have exactly the same incentive to sell high quality and to deviate from high quality and sell low quality in an attempt to fool the public and gain short-term profits.

Consider the following simple equilibrium. Each firm sells high quality every period and charges $p^{*}$. If a firm deviates to low quality, it sells low quality in every subsequent period for zero. Each consumer's strategy is as follows. If there is at least one firm that has never sold low quality, then the consumer purchases one unit from such a firm that is offering the product at the lowest price greater than or equal to $p^{*}$ as long as that price is lower than $v$. If there are several firms selling the product at the same low price greater than or equal to $p^{*}$, that have not sold lowquality in the past, then each consumer chooses among those firms randomly and it is assumed that purchases, in aggregate, are spread equally among the firms. If there are no firms which have never sold low quality and that are selling at price greater than or equal to $p^{*}$ but lower than $v$, the consumer buys one unit of low quality or buys nothing. Consumers believe that a firm selling a good for $p^{*}$ is selling high quality. Out of equilibrium, if a firm deviates to $p<p^{*}$, the consumer believes that the firm is producing low quality; if a firm deviates to $p>p^{*}$, the consumer believes the firm is producing high quality.

It is easy to confirm that the previous paragraph describes an equilibrium in which firms sell high quality if $v>p^{*}$. Firms will not deviate and sell low quality (or nothing), because $p^{*}$ was defined as the price at which the firm was indifferent between producing high quality and low quality (or nothing); producing low quality in one period generates profits in that period, but zero profits in all later periods, because consumers refuse to buy from the firm. Similarly, firms will not deviate and charge a higher price, because then they would have no sales and earn zero. Since, according to (2), $p^{*}$ generates profits for the firm, it would rather sell high quality at $p^{*}$ than earn nothing. If a firm did deviate and sell low quality, it would continue to sell low quality or sell nothing in all future periods, because consumers would never pay the high-quality price to 
purchase from them again. Given that firms are producing high quality and selling at $p^{*}$, it is rational for consumers to buy at that price from any firm that has not sold low quality. Given that a firm that has sold low quality once will always sell low quality or sell nothing, it is rational for consumers never to buy from such a firm. Consumer beliefs are also rational, because firms charging $p^{*}$ or more have an incentive to sell high quality, while firms charging less do better by producing low quality (or not producing anything at all). ${ }^{7}$

Note that there would not be an equilibrium in which firms sell high quality with a price lower than $p^{*}$, because firms would do better by producing low quality. Note also that there could be an equilibrium in which all firms sold high quality and sold their goods at a price higher than $p^{*}$, but it would require consumers to believe that firms that sold between $p^{*}$ and the equilibrium price were producing low quality, which is irrational. There are, of course, other equilibria. For example, it would be an equilibrium for consumers only to buy low-quality and firms only to sell low-quality. Also, there are equilibria in which consumers punish firms that sell low-quality for a finite number of periods. For simplicity and in order to focus on reputational economies of scale, this paper, like Rasmusen (2016), analyzes only grim trigger strategies that result in the production of high-quality products.

Having described the equilibrium of interest, we can turn to the issue of primary concern: reputational economies of scale.

Proposition 1. There are no reputational economies of scale in the basic infinite-horizon model.

Proof. The proof follows simply from the incentive-compatibility constraint, (1), and the quality assuring price, (2). The lowest price consistent with the incentive compatibility constraint does not vary by quantity, $q_{i}$. Firms that sell larger qualities cannot credibly sell high-quality at a lower price when those producing lower quantities.

Given that larger firms and small firms have the same incentive compatibility constraint and can credibly sell high-quality goods at the same price, it is also possible that there is an equilibrium in which firms of different sizes all sell in the same market. For example, if, consumers chose firms randomly from among those selling at or above $p^{*}$ and that had not sold

${ }^{7}$ In this equilibrium, all potential firms enter the market and every consumer buys one unit. This makes sense if the number of firms equals the number of consumers divided by the quantity term sells, $N=\frac{Q}{q i}$. In Rasmusen $(1989,2007)$ there is a fixed cost, $F$, of entry that ensures that all firms make zero profits and determines the number of firms that enter. As in Rasmusen (2016), the model here assumes zero fixed cost and some exogenous limit on the number of firms that can enter the market so that competition is consistent with positive profits and so the aggregate supply equals aggregate demand. Alternatively, one could assume fixed costs, $F=\frac{q_{i}\left(p^{*}-c\right)}{r}=c q_{i}$. If one takes this approach, the number of firms is endogenous, $N=\frac{Q}{q i}=\frac{Q c}{F}$. 
low quality goods, but were more likely to choose some firms over others, some firms would have a larger quantities, but the price would be the same. For example, if there were $N_{L}$ large firms, $N_{S}$ small firms, and $Q$ consumers with $v>p^{*}$, then it would be an equilibrium for each consumer to choose to purchase a product with probability $\frac{2}{3\left(N_{L}+N_{S}\right)}$ from each large firm and probability $\frac{1}{3\left(N_{L}+N_{S}\right)}$ from each small firm, for large firms to sell twice as much a small firms, for all firms to sell at same price, $p^{*}$, and for all to sell high-quality. ${ }^{8}$

3. Reputational Economies of Scale When Low Quality Is Detected With Probability Less Than One

A key assumption in the prior section was that consumers detect and punish low quality with probability one at the end of each period. That is obviously unrealistic. It is more reasonable to assume that consumers detect and punish low quality with probability less than one, but that the probability increases as the firm sells more low-quality goods. That is, let $s\left(k_{i}\right)$ be the probability that consumers detect and punish low quality if $k_{i}$ low quality units are sold, where $0 \leq k_{i} \leq q_{i}, s(0)=0, \lim _{k_{i} \rightarrow \infty} s\left(k_{i}\right)=1, s^{\prime}>0$, and $s^{\prime \prime}<0$. The assumption that the second derivative is negative follows largely (but not entirely) from the idea that $s\left(k_{i}\right)$ is increasing but must take values between zero and one, whereas $k_{i}$ can be any positive real number. That means that the second derivative would need to be negative over most of its range (although it could be zero or positive over some intervals). It simplifies the math to assume that the second derivative is always negative. The probability of detection and punishment might increase because media are more likely to publicize defects in products that are more widely distributed. ${ }^{9}$ Another possible mechanism would be to assume that the probability with which the low quality of any particular unit purchased is detected is $\rho, 0<\rho<1$, and independent. One could then interpret $s$ to be the probability that low quality is detected in at least one unit sold by a firm in a given period, under the assumption that consumers will punish the firm if it sells any low quality. Under this interpretation, if $k_{i}$ low quality units are sold, $s=1-(1-\rho)^{k_{i}}$. Another interpretation might be that $s\left(k_{i}\right)$ is the fraction of consumers who refuse to buy from the firm that has sold low quality. That probability might go up with the number of low-quality units sold, because knowledge of low quality is more likely to diffuse, either through word of mouth or through media, when the number of defective products is larger.

Assume provisionally that the firm sells either all high quality or all low quality, that is $k_{i} \in$ $\left\{0, q_{i}\right\}$. Appendix A shows that this assumption is justified, because it would not be rational for a

${ }^{8}$ For different firm sizes to be consistent with free entry and zero profits, as discussed in the previous footnote, large and small firms would have to have different fixed costs. That is, fixed costs would have to be proportional to output. This makes sense: firms with greater capacity need to invest more in plant and equipment.

${ }^{9}$ Large firms may, however, may be better able to manipulate the media or mitigate the effects of negative publicity through their own advertising and public relations. The author thanks Joshua Teitelbaum for this insight. 
firm to sell some high and some low quality. ${ }^{10}$ Because the probability of detection, $s$, increases with the quantity of low-quality goods, the incentive-compatibility constraint - see (1) above needs to be modified to take into account that cheating is discovered with probability less than one. The payoff of consistently producing high quality remains the same, but the payoff to producing low quality is more complicated, because a firm producing low quality goods may now get the high payoff for several periods until the low quality of its products is detected:

$$
\begin{gathered}
\frac{q_{i}(p-c)}{r} \geq \frac{q_{i} p}{1+r}+(1-S) \frac{q_{i} p}{(1+r)^{2}}+(1-s)^{2} \frac{q_{i} p}{(1+r)^{3}}+\cdots \\
\geq \sum_{j=1}^{\infty}(1-s)^{j-1} \frac{q_{i} p}{(1+r)^{j}} \\
\geq \frac{q_{i} p}{(1+r)} \sum_{j=0}^{\infty}\left(\frac{1-s}{1+r}\right)^{j} \\
\geq \frac{q_{i} p}{(1+r)}\left(\frac{1}{1-\left(\frac{1-s}{1+r}\right)}\right) \\
\geq \frac{q_{i} p}{r+s}
\end{gathered}
$$

Changing the inequality to an equality and solving for $p$ yields the quality-assuring price. Let $p^{\prime *}$ denote the quality-assuring price under the assumptions in this section (e.g. that the probability of detection is less than one):

$$
p^{\prime *}=\frac{(r+s) c}{s}=\frac{r c}{s}+c
$$

${ }^{10}$ Although the literature often assumes that firms are constrained to offering either all highquality or all low-quality, it is useful to check that the quality assuring price does not give firms an incentive to produce some high quality and some low-quality product. After all, this and most other models in the literature assume fixed marginal cost, so there is no loss in economies of scale if a firm chose to produce some high quality and some low quality. Appendix A proves that, under the quality assuring price in Equation (4), a firm rationally produces all high quality rather than a mixture of qualities. This result could also by justified if one assumed that producing the fixed cost, $F$, was incurred for each quality, e.g. if each quality required a different factory and/or separate management structure. 
As one would expect, as the probability of detection, $s$, goes to one, $p^{*}$ in (4) converges to $p^{*}$ in (2). Note, however, that since $s$ is a function of quantity, the quality-assuring price now varies with the quantity sold by each firm, $q_{i}$. In particular, as $q_{i}$ approaches infinity, $s$ approaches one, and price approaches $(1+r) c$. On the other hand, as $q_{i}$ approaches zero, $s$ approaches 0 , and $p^{\prime *}$ approaches infinity. It is relatively easy to see that $p^{\prime *}$ is a strictly monotonically decreasing function of $q_{i}$. This makes intuitive sense. When quantity is low, the probability of detection is low, so the firm needs a high price to make it worthwhile not to cheat. This is closely related to the standard result in the economic analysis of crime, where optimal sanctions increase as the probability of detection goes down (Becker (1968), Stigler (1970)). In the reputation model, the "sanction" for cheating is loss of the rents produced by receiving the high price in every period. On the other hand, as the probability of detection increases, the firm finds it profitable to sell high quality even if the price is lower.

This is the key result of the paper. Since the quality-assuring price for a firm goes down as the firm sells higher quantities, the larger firm has an advantage. It can sell at a lower price and still have an incentive to sell high quality. This is the meaning of reputational economies of scale and leads directly to Proposition 2.

Proposition 2. There are reputational economies of scale in the infinite-horizon model when low quality is detected with probability less than one.

Proof. The proof follows simply from the quality-assuring price, (4). The lowest price consistent with the incentive-compatibility constraint, (3), varies with, $s$, the probability that low quality will be detected: as that probability goes up, the quality assuring price goes down. Because that probability, $s$, is an increasing function of quantity, $q_{i}$, firms that sell larger qualities can credibly sell high-quality at a lower price than those producing lower quantities.

Other than the relevant price being $p^{\prime *}$ rather than $p^{*}$, the equilibrium described in the prior section works equally well for the model described here where the probability of detection of low quality is less than one. ${ }^{11}$ Because the quality-assuring price varies with quantity, there is no plausible equilibrium with both large and small firms producing high quality. For such an equilibrium to exist, the price paid to smaller firms would have to be the higher price necessary to give such firms an incentive to sell high quality. This means consumers must be either (a) willing to pay different prices to small and large firms selling goods of the same quality, or (b) unwilling to purchase high-quality goods at lower prices from larger firms. (a) is incompatible

${ }^{11}$ To make the equilibrium consistent with free entry and zero profits, fixed costs would be $F=$ $\frac{q_{i}\left(p^{*}-c\right)}{r}$. Substituting $p^{\prime *}=\frac{(r+s) c}{s}$, we can derive the equilibrium quantity, $q_{i}^{\prime *}=\frac{s F}{c}$, and number of firms, $n^{\prime *}=\frac{Q}{q_{i}^{\prime *}}$. Note that there would need to be some additional, but relatively trivial, constraints on parameters $s, F$, and $c$ in order for $q_{i}^{\prime *}$ to be at least 1 and $n^{\prime *}$ to be at least 2 . 
with consumer rationality. If consumers believed that even larger firms were selling low quality if they sold at prices between the quality-assuring price for large and small firms, then there is an equilibrium (b) in which all firms received the high price necessary to induce even smaller firms to sell high-quality, and both large and small firms could exist in the same market. Nevertheless, this seems implausible because it would require consumers to believe that large firms would sell low quality when selling at a price for which it would be advantageous for them to sell high quality.

It should be noted that the equilibrium described in this section is informationally demanding. Both consumers and firms need to know the quality-assuring price, and this requires that both consumers and firms know the cost of producing high quality goods, the discount rate, and the probability that low quality will be detected, and the number of goods sold by each firm. The need for the first two pieces of information is a characteristic of the basic infinitely repeated game model of reputation. The need for the other information is, however, an additional requirement of the modified model presented in this section. Rasmusen and Perri (2001) suggest, using a more sophisticated model, that it might be possible to relax some of these informational requirements. Further research could explore the extent to which the results in this section are robust to parties estimating the parameters with error. In the real world, consumers do seem to have some sense that certain low prices are "too good to be true." This suggests that the model's prediction that consumers would refuse to buy from firms that charged too low a price has some plausibility.

\section{Umbrella Branding}

Now consider what would happen if some firms sell multiple goods while others sell only one good. For simplicity, suppose there are two goods, A and B, and three types of firms, firms that sell only A, firms that sell only B, and firms that sell both A and B. This section will show that firms that sell both A and B will be able to sell high quality of both A and B at lower prices than firms that sell only A or only B. This establishes the core idea of reputational economies of scale - larger firms that sell more products have a competitive advantage over smaller ones. The intuition for this result is the same as for the result in the previous section. A firm that sells both goods sells more total goods, so, because the quality-assuring price falls with quantity, the firm selling both goods will be able to credibly sell high-quality goods at a lower cost. Nevertheless, the math demonstrating this result is more complicated.

The analysis in this section depends crucially on how consumers react to the detection of low quality in one product sold by a firm that sells multiple products. If a consumer purchases product $\mathrm{A}$ and it turns out to be of low quality, the consumer might cease purchasing product $\mathrm{A}$ from that firm, but still purchase product B from it. Or, such a consumer might shun all products from that firm, that is, avoid purchasing both A and B from it. If consumers behave in the former way - treating low quality in one product as irrelevant to the quality of other products sold by the same firm - then there is no advantage to the two-product firm. On the other hand, if, as seems 
plausible, consumers interpret low quality in one product to mean that the firm is cutting corners on both products, then it makes sense for them to refuse to purchase A or B from that firm. If so, a new and interesting equilibrium arises. That is the equilibrium that will be analyzed in the rest of this section. This equilibrium is plausible in situations where a firm has chosen to market two or more products under the same trademark - for example, several different car models under the trademark "Toyota" or several types of toothpaste under the trademark "Colgate." In these situations, it is plausible that consumers assume that quality standards are similar for all products marketed under the same "umbrella trademark."

Our notation needs to be modified to reflect that there are now two different goods. There is a large number of consumers, $Q>N$, each of whom is willing to pay up to $v_{A}$ for one unit of high-quality good $\mathrm{A}$, up to $v_{B}$ for one unit of high-quality good $\mathrm{B}$, and zero for the low-quality of A or B. Denote the quantity of good A sold by firm $i$ as $q_{A_{i}}$, and the quantity of good B sold by such a firm as $q_{B_{i}}$. As in previous sections, these quantities will initially be assumed to be exogenous. Denote the cost of producing high quality of each good as $c_{A}>0$ and $c_{B}>0$. Let $s_{A_{i}}\left(k_{A_{i}}\right)$ be the probability that low quality is detected and punished if the firm sells $k_{A_{i}}$ low quality units of product $\mathrm{A}$, but either no product $\mathrm{B}$ or only high quality of product $\mathrm{B}$. Let $s_{B_{i}}\left(k_{B_{i}}\right)$ be the probability that low quality is detected and punished, if the firm sells $k_{B_{i}}$ low quality units of product $\mathrm{B}$, but either no product $\mathrm{A}$ or only high quality of product $\mathrm{A}$. Let $s_{A B_{i}}\left(k_{A_{i}}, k_{B_{i}}\right)$ be the probability that low quality is detected and punished, if the firm sells $k_{A_{i}}$ low-quality units of A and $k_{B_{i}}$ low quality units of B. $0 \leq k_{A_{i}} \leq q_{A_{i}}$ and $0 \leq k_{B_{i}} \leq q_{B_{i}}$. As with the one good case, assume $s_{u_{i}}(0)=0, \lim _{k_{u_{i}} \rightarrow \infty} s_{u_{i}}\left(k_{u_{i}}\right)=1, s_{u_{i}}^{\prime}>0$, and $s_{u_{i}}{ }^{\prime \prime}<0$, where $u \in\{A, B\}$. Similarly, $s_{A B_{i}}(0,0)=0, s_{A B_{i}}\left(0, k_{B_{i}}\right)=s_{B_{i}}\left(k_{B_{i}}\right), s_{A B_{i}}\left(k_{A_{i}}, 0\right)=s_{A_{i}}\left(k_{A_{i}}\right)$, $\lim _{k_{A_{i}}+k_{B_{i}} \rightarrow \infty} s_{A B_{i}}\left(k_{A_{i}}, k_{B_{i}}\right)=1, \frac{d s_{A B_{i}}}{d k_{u_{i}}}>0$ and $\frac{d^{2} s_{A B_{i}}}{d^{2} k_{u_{i}}}>0$. Note that these assumptions imply that if the firm sells positive quantities of both low quality A and B, then $s_{A B_{i}}\left(k_{A_{i}}, k_{B_{i}}\right)>s_{A_{i}}\left(k_{A_{i}}\right)$ and $s_{A B_{i}}\left(k_{A_{i}}, k_{B_{i}}\right)>s_{B_{i}}\left(k_{B_{i}}\right)$. This makes sense, because if two firms sell the same number of low quality goods of kind $\mathrm{A}$, and one of them also sells low-quality goods of kind $\mathrm{B}$, it is more likely that the firm that sells two types of low-quality goods will be caught. After all, the probability that the two-good firm is caught making low-quality goods of kind A should be the same as the probability that the one-good firm is caught making low-quality goods of kind A, but the twogood firm also has some probability of being caught making low-quality goods of kind B. Under the interpretation that the probabilities with which the low quality of any particular unit purchased of good A or B is detected are $\rho_{A}>0$ and $\rho_{B}>0$, where these two probabilities are

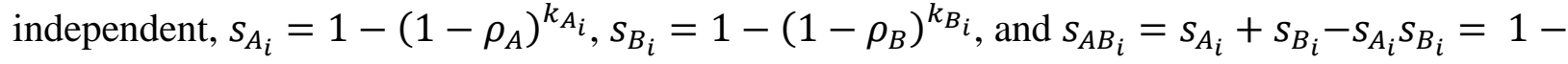
$\left(1-\rho_{A}\right)^{k_{A_{i}}}\left(1-\rho_{B}\right)^{k_{B_{i}}}$. Note that, under this interpretation, the assumptions made above, that $s_{A B_{i}}\left(k_{A_{i}}, k_{B_{i}}\right)>s_{A_{i}}\left(k_{A_{i}}\right)$ and $s_{A B_{i}}\left(k_{A_{i}}, k_{B_{i}}\right)>s_{B_{i}}\left(k_{B_{i}}\right)$, are always true when the firm sells both low goods of both goods (e.g. $k_{A_{i}}>0$ and $k_{B_{i}}>0$ ). 
As in the previous section, assume provisionally that the firm does not mix high and low quality for a given product. That is, if the firm sells A, all units of A are high quality or all are low quality. Similarly, if the firm sells B, all units of B are high quality or all are low quality. Appendix A shows that this assumption is justified, because it would not be rational for a firm to sell some high and some low quality of each product.

As in the previous sections, start with the incentive-compatibility constraints. There are now three.

$\mathrm{C} 1$. High quality on both A and B at least as profitable as low quality on both A and B:

$$
\frac{q_{A_{i}}\left(p_{A}^{\prime}-c_{A}\right)+q_{B_{i}}\left(p_{B}^{\prime}-c_{B}\right)}{r} \geq \frac{q_{A_{i}} p_{A}^{\prime}+q_{B_{i}} p_{B}^{\prime}}{\left(r+s_{A B_{i}}\right)}
$$

C2. High quality on both A and B at least as profitable as high quality on B and low quality on A:

$$
\frac{q_{A_{i}}\left(p_{A}^{\prime}-c_{A}\right)+q_{B_{i}}\left(p_{B}^{\prime}-c_{B}\right)}{r} \geq \frac{q_{A_{i}} p_{A}^{\prime}+q_{B_{i}}\left(p_{B}^{\prime}-c_{B}\right)}{\left(r+s_{A_{i}}\right)}
$$

C3. High quality on both A and B at least as profitable as high quality on A and low quality on B:

$$
\frac{q_{A_{i}}\left(p_{A}^{\prime}-c_{A}\right)+q_{B_{i}}\left(p_{B}^{\prime}-c_{B}\right)}{r} \geq \frac{q_{A_{i}}\left(p_{A}^{\prime}-c_{A}\right)+q_{B_{i}} p_{B}^{\prime}}{\left(r+s_{B_{i}}\right)}
$$

Because there is not a unique pair of quality-assuring prices, $\left(p_{A}^{\prime *}, p_{B}^{\prime *}\right)$, identification of the quality-assuring prices is deferred to the proof of Proposition 3.

Proposition 3. Umbrella branding creates reputational economies of scale in the infinitehorizon model when low quality is detected with probability less than one. That is, a twoproduct firm that sells $q_{A_{i}}$ of product $A$ and $q_{B_{i}}$ of product $B$ can credibly sell high quality of both products at a lower price than one-product firms that sell only $q_{A_{i}}$ of product $A$ or $q_{B_{i}}$ of product $B$.

Proof. Consider first Lemma 1:

Lemma 1. If firms selling both $A$ and $B$ choose prices and quantities that would be quality-assuring for firms selling just $A$ or just $B$, then constraints $C 1, C 2$, and $C 3$ would be satisfied with strict inequalities. That is, if, following (4) above,

$$
p_{A}^{\prime}=\frac{\left(r+s_{A_{i}}\right) c_{A}}{s_{A_{i}}} \text { and } p_{B}^{\prime}=\frac{\left(r+s_{B_{i}}\right) c_{B}}{s_{B_{i}}} \text {, then } C 1, C 2 \text { and } C 3 \text { would hold with strict }
$$
inequalities. 
Proof of Lemma. First consider C1. To prove:

$$
\frac{q_{A_{i}}\left(p_{A}^{\prime}-c_{A}\right)+q_{B_{i}}\left(p_{B}^{\prime}-c_{B}\right)}{r}>\frac{q_{A_{i}} p_{A}^{\prime}+q_{B_{i}} p_{B}^{\prime}}{\left(r+s_{A B_{i}}\right)}
$$

Substitute $p_{A}^{\prime}=\frac{\left(r+s_{A_{i}}\right) c_{A}}{s_{A_{i}}}$ and $p_{B}^{\prime}=\frac{\left(r+s_{B_{i}}\right) c_{B}}{s_{B_{i}}}$ and simplify:

$$
\begin{aligned}
& \frac{q_{A_{i}}\left(\frac{\left(r+s_{A_{i}}\right) c_{A}}{s_{A_{i}}}-c_{A}\right)+q_{B_{i}}\left(\frac{\left(r+s_{B_{i}}\right) c_{B}}{s_{B_{i}}}-c_{B}\right)}{r}>\frac{q_{A_{i}} \frac{\left(r+s_{A_{i}}\right) c_{A}}{s_{A_{i}}}+q_{B_{i}} \frac{\left(r+s_{B_{i}}\right) c_{B}}{s_{B_{i}}}}{\left(r+s_{A B_{i}}\right)} \\
& \frac{q_{A_{i}} c_{A}}{s_{A_{i}}}+\frac{q_{B_{i}} c_{B}}{s_{B_{i}}}>\frac{q_{A_{i}} c_{A}}{s_{A_{i}}}\left(\frac{r+s_{A_{i}}}{r+s_{A B_{i}}}\right)+\frac{q_{B_{i}} c_{B}}{s_{B_{i}}}\left(\frac{r+s_{B_{i}}}{r+s_{A B_{i}}}\right)
\end{aligned}
$$

$s_{A B_{i}}>s_{A_{i}}>0$ and $s_{A B_{i}}>s_{B_{i}}>0$ (see p. 11), so the above inequality always holds.

Next consider C2: To prove:

$$
\frac{q_{A_{i}}\left(p_{A}^{\prime *}-c_{A}\right)+q_{B_{i}}\left(p_{B}^{\prime *}-c_{B}\right)}{r}>\frac{q_{A_{i}} p_{A}^{\prime *}+q_{B_{i}}\left(p_{B}^{\prime *}-c_{B}\right)}{\left(r+s_{A_{i}}\right)}
$$

As with $\mathrm{C} 1$, substitute $p_{A}^{\prime *}=\frac{\left(r+s_{A_{i}}\right) c_{A}}{s_{A_{i}}}$ and $p_{B}^{\prime *}=\frac{\left(r+s_{B_{i}}\right) c_{B}}{s_{B_{i}}}$ and simplify:

$$
\frac{q_{A_{i}} c_{A}}{s_{A_{i}}}+\frac{q_{B_{i}} c_{B}}{s_{B_{i}}}>\frac{q_{A_{i}} c_{A}}{s_{A_{i}}}+\frac{q_{B_{i}} c_{B}}{s_{B_{i}}}\left(\frac{r}{r+s_{A_{i}}}\right)
$$

$r>0$ and $s_{A_{i}}>0$, so the above inequality always holds.

Similar reasoning shows that C3 also holds with strict inequality. Q.E.D.

Now we need to define and prove the existence of quality-assuring prices, $\left(p_{A}^{\prime *}, p_{B}^{\prime *}\right)$. In prior sections, the quality-assuring price was found by solving the incentive-compatibility constraint as an equality. Unfortunately, in general, there is no pair of prices, $\left(p_{A}^{\prime *}, p_{B}^{\prime *}\right)$, that satisfies all three incentive-compatibility constraints $-\mathrm{C} 1$, $\mathrm{C} 2$, and $\mathrm{C} 3$ - if they are set to equality. So, we will say that a pair of prices is a qualityassuring price if at least one of the three incentive-compatibility constraints holds with equality. Unfortunately, there are an infinite number of such pairs. For our purposes, it is sufficient to identify and prove the existence of a single such pair.

Consider ordered pairs, $\left(p_{A}, p_{B}\right)$ and, in particular the set of ordered pairs constituting the line segment between $\left(c_{A}, c_{B}\right)$ and $\left(\frac{\left(r+s_{A_{i}}\right) c_{A}}{s_{A_{i}}}, \frac{\left(r+s_{B_{i}}\right) c_{B}}{s_{B_{i}}}\right)$. The first point 
is defined by the marginal cost of producing each good, and the second point is defined by the quality-assuring prices when a firm sells only good A or only good B. Note that at $\left(c_{A}, c_{B}\right), \mathrm{C} 1, \mathrm{C} 2$, and $\mathrm{C} 3$ will be each violated, because the left-hand sides will be zero and the right-hand sides will be positive. Note also that, according to Lemma 1, at $\left(\frac{\left(r+s_{A_{i}}\right) c_{A}}{s_{A_{i}}}, \frac{\left(r+s_{B_{i}}\right) c_{B}}{s_{B_{i}}}\right), \mathrm{C} 1, \mathrm{C} 2$ and $\mathrm{C} 3$ each hold with strict inequalities.

Now consider what happens to $\mathrm{C} 1$ as one moves along the line from $\left(\frac{\left(r+s_{A_{i}}\right) c_{A}}{s_{A_{i}}}, \frac{\left(r+s_{B_{i}}\right) c_{B}}{s_{B_{i}}}\right)$ to $\left(c_{A}, c_{B}\right)$. Since the inequality in $\mathrm{C} 1$ holds strictly at $\left(\frac{\left(r+s_{A_{i}}\right) c_{A}}{s_{A_{i}}}, \frac{\left(r+s_{B_{i}}\right) c_{B}}{s_{B_{i}}}\right)$ and is violated at $\left(c_{A}, c_{B}\right)$, and since both sides vary continuously with $p_{A}$ and $p_{B}$, there must be a place on the line between those two points where the lefthand and right-hand sides are equal. If there is only one such point, call that point $\left(x_{1}, y_{1}\right)$. If there is more than one such point, denote as $\left(x_{1}, y_{1}\right)$ the one with the highest value of $p_{A}$. Note that, for all points on the line between $\left(x_{1}, y_{1}\right)$ and $\left(\frac{\left(r+s_{A_{i}}\right) c_{A}}{s_{A_{i}}}, \frac{\left(r+s_{B_{i}}\right) c_{B}}{s_{B_{i}}}\right), \mathrm{C} 1$ holds with strict inequality, because if it held with equality that would violate the definition of $\left(x_{1}, y_{1}\right)$, and if the inequality did not hold at all, then, because of continuity, there would have to be another point in that interval where $\mathrm{C} 1$ held with equality, which would also violate the definition of $\left(x_{1}, y_{1}\right)$.

By similar reasoning, let $\left(x_{2}, y_{2}\right)$ be the sole point where $\mathrm{C} 2$ holds with equality on the line segment between $\left(c_{A}, c_{B}\right)$ and $\left(\frac{\left(r+s_{A_{i}}\right) c_{A}}{s_{A_{i}}}, \frac{\left(r+s_{B_{i}}\right) c_{B}}{s_{B_{i}}}\right)$ or the one with the highest value of $p_{A}$. C2 will hold with strict inequality for every point between $\left(x_{2}, y_{2}\right)$ and $\left(\frac{\left(r+s_{A_{i}}\right) c_{A}}{s_{A_{i}}}, \frac{\left(r+s_{B_{i}}\right) c_{B}}{s_{B_{i}}}\right)$.

By similar reasoning, let $\left(x_{3}, y_{3}\right)$ be the sole point where $\mathrm{C} 3$ holds with equality on the line segment between $\left(c_{A}, c_{B}\right)$ and $\left(\frac{\left(r+s_{A_{i}}\right) c_{A}}{s_{A_{i}}}, \frac{\left(r+s_{B_{i}}\right) c_{B}}{s_{B_{i}}}\right)$ or the one with the highest value of $p_{A}$. C3 will hold with strict inequality for every point between $\left(x_{3}, y_{3}\right)$ and $\left(\frac{\left(r+s_{A_{i}}\right) c_{A}}{s_{A_{i}}}, \frac{\left(r+s_{B_{i}}\right) c_{B}}{s_{B_{i}}}\right)$.

$$
\text { Let }\left(p_{A}^{\prime *}, p_{B}^{\prime *}\right)=\left\{\begin{array}{l}
\left(x_{1}, y_{1}\right) \text { if } x_{1} \geq x_{2} \text { and } x_{1} \geq x_{3} \\
\left(x_{2}, y_{2}\right) \text { if } x_{2}>x_{1} \text { and } x_{2} \geq x_{3} \\
\left(x_{3}, y_{3}\right) \text { if } x_{3}>x_{1} \text { and } x_{3}>x_{2}
\end{array}\right.
$$


By construction, all 3 incentive-compatibility constraints $-\mathrm{C} 1$ through $\mathrm{C} 3$ - are satisfied at these prices. In addition, by construction, these prices are lower than $\left(\frac{\left(r+s_{A_{i}}\right) c_{A}}{s_{A_{i}}}, \frac{\left(r+s_{B_{i}}\right) c_{B}}{s_{B_{i}}}\right)$, the quality-assuring prices for firms selling only product A or product B. ${ }^{12}$ Q.E.D.

As in the previous two sections, we now show that those prices are part of a plausible equilibrium. Consider the following set of strategies that form a perfect equilibrium.

Let $p_{A}^{\prime *}$ and $p_{B}^{\prime *}$ be the pair of prices identified in the Proof of Proposition 3 as satisfying incentive-compatibility constraints $\mathrm{C} 1-\mathrm{C} 3$.

(1) If there is at least one firm that has never sold low quality, then the consumer purchases one unit of A from such a firm that is offering the product at the lowest price greater than or equal to $p_{A}^{\prime *}$ as long as that price is lower than $v_{A}$. If there are several firms selling the product at the same low price greater than or equal to $p_{A}^{\prime *}$, that have not sold low-quality in the past, then each consumer chooses among those firms randomly and it is assumed that purchases, in aggregate, are spread equally among the firms. If there are no firms which have never sold low quality and that are selling at price greater than or equal to $p_{A}^{\prime *}$ but lower than $v_{A}$, the consumer buys no $\mathrm{A}$. Consumers believe that a firm selling a good for $p_{A}^{\prime *}$ is selling high quality. Out of equilibrium, if a firm deviates to $p<$ $p_{A}^{\prime *}$, the consumer believes that the firm is producing low quality; if a firm deviates to $p>p_{A}^{\prime *}$, the consumer believes the firm is producing high quality.

(2) If there is at least one firm that has never sold low quality, then the consumer purchases one unit of $\mathrm{B}$ from such a firm that is offering the product at the lowest price greater than or equal to $p_{B}^{\prime *}$ as long as that price is lower than $v_{B}$. If there are several firms selling the product at the same low price greater than or equal to $p_{B}^{\prime *}$, that have not sold

${ }^{12}$ Note that there are an infinite number of ordered pairs $\left(p_{A}^{\prime *}, p_{B}^{\prime *}\right)$, satisfying $\mathrm{C} 1, \mathrm{C} 2$, and $\mathrm{C} 3$. Their existence can be proved by considering the family of curves (e.g. increasingly concave or convex bowed-out lines) passing through $\left(c_{A}, c_{B}\right)$ and $\left(\frac{\left(r+s_{A_{i}}\right) c_{A}}{s_{A_{i}}}, \frac{\left(r+s_{B_{i}}\right) c_{B}}{s_{B_{i}}}\right)$, but overlapping or intersecting the straight line between those points only at the endpoints. By reasoning similar to the above for straight lines, each of those curves will also have a point where at least one of $\mathrm{C} 1, \mathrm{C} 2$, and $\mathrm{C} 3$ hold with equality, and that point will not be on the straight line, so it will be different than $\left(p_{A}^{\prime *}, p_{B}^{\prime *}\right)$. For the purposes of this paper, it is sufficient to prove that there is just one such ordered pairs. Consideration of additional pairs satisfying the constraints introduces complications, such as how consumers coordinate on one pair of prices. By just considering the pair whose existence was proved first, such complications can be avoided. 
low quality in the past, then each consumer chooses among those firms randomly and it is assumed that purchases, in aggregate, are spread equally among the firms. If there are no firms which have never sold low quality and that are selling at price greater than or equal to $p_{B}^{\prime *}$ but lower than $v_{B}$, the consumer buys no $\mathrm{B}$. Consumers believe that a firm selling a good for $p_{B}^{\prime *}$ is selling high quality. Out of equilibrium, if a firm deviates to $p<p_{B}^{\prime *}$, the consumer believes that the firm is producing low quality; if a firm deviates to $p>p_{B}^{\prime *}$, the consumer believes the firm is producing high quality.

(3) Firms that sell both A and B sell both at high quality and sell them at prices $p_{A}^{\prime *}$ and $p_{B}^{\prime *}$ respectively. If a firm deviates to low quality, it sells low quality of both A and B in every subsequent period for zero. ${ }^{13}$

It is easy to confirm that those strategies form an equilibrium. Given that the prices satisfy the incentive-compatibility constraints, it is in the best interest of firms to sell highquality and sell at those prices. Producing low quality yields a lower payoff. Charging a higher or lower price also yields lower payoffs because there would be no sales and thus no profits. Given that the firms are producing high quality and selling at those prices, it is in the best interests of consumers to buy from them, assuming the prices are lower than $v_{A}$ and $v_{B}$. Given consumer beliefs, their off-equilibrium strategies are rational. Given firms' incentive-compatibility constraints, consumers' out-of-equilibrium beliefs are rational.

Given that two-product firms can sell high-quality goods at prices that would violate the incentive-compatibility constraints of single-product firms, it is hard to imagine a plausible equilibrium in which both two-product firms and single-product firms would coexist. The reasoning is similar to that set out in the prior section about the implausibility of large and small firms coexisting in the same market if low quality is detected with probability less than one: larger firms can credibly commit to producing high quality at lower prices.

Note, of course, that there are many equilibria, including equilibria in which both twoproduct and single-product firms sell goods of similar quality. The most obvious (and uninteresting) is the equilibrium in which consumers purchase only products sold at the lowquality price (here normalized to zero) and in which all firms sell only low quality. A more

${ }^{13}$ To make the equilibrium consistent with free entry and zero profits, one needs, as in prior sections, to introduce fixed costs. Let $F_{A}>0$, and $F_{B}>0$ be the fixed costs of producing $\mathrm{A}$ and $\mathrm{B}$ respectively. As in the one-good case, these costs are paid at the beginning of the first period in which the firm produces the relevant good. Note that $F_{A}$ does not depend on whether the firm produces one or two goods, nor does $F_{B}$. That is, there are no economies of scope attributable to the fixed costs. This assumption, like the assumption of constant marginal costs, allows the analysis to focus economies scale created by reputation rather than by technological factors. For each pair of quality-assuring prices $\left(p_{A}^{\prime *}, p_{B}^{\prime *}\right)$ and other parameters, there is a pair of fixed costs, $\left(F_{A}, F_{B}\right)$ that assures zero profits and the desired number of firms and quantities per firm. In the equilibrium set out in the text, $q_{A_{i}}=q_{B_{i}}$, because consumers purchase the same amount of A and B. Different quantities could easily be obtained in equilibrium by varying consumer demand. 
interesting equilibrium is one in which consumers favor single-product firms by buying from them with higher probability, even if the single-product firm offers the good at the same price as the two-product firm. By doing so, consumers could negate the scale advantage of the twoproduct firm by purchasing, in aggregate, more of the single good from the single-product firm. For example, suppose goods A and B are similar in that the cost of producing high quality is equal, $c_{A}=c_{B}$, and the probability that low quality is detected depends solely on the total number of low quality goods sold by that firm, $k, s_{A_{i}}(k)=s_{B_{i}}(k)=s_{A B_{i}}(k / 2, k / 2)_{B}$. Under those assumptions, there would be an equilibrium in which each consumer purchased randomly from all firms, but in which the probability with which the consumer purchased from each single-good firm was twice the probability with which the consumer purchased from each twogood firm. If consumers behaved in this fashion, each two-product firm would sell half as much of each good as each single-product firm. So the total sales (A and B combined) of the twoproduct firms would equal the sales of the single-product firm. So the quality-assuring price for both products would be the same for two-product and one-product firms. While interesting, this equilibrium assumes implausible consumer behavior

So far, this paper has assumed that consumers value high quality so much that they would buy it even at the price offered by single-product firms. As Rasmusen (2016) points out, however, it is possible that consumers will prefer low quality to high quality at the qualityassuring price that could be offered by a single-product firm. The existence of multi-product firms can, in some circumstances, solve this problem by lowering the quality-assuring price. In this way, umbrella branding (the use of a single trademark for several products sold by the same firm) makes high quality viable in situations where, if the same product were sold by a singleproduct firm, high quality would require a quality-assuring price that consumers were unwilling to pay. Note, contrary to Rasmusen, umbrella branding makes high quality viable even in the presence of perfect competition.

While this section focused on umbrella branding, the law firm size issue explored by Iacobucci (2012) is analytically identical. Instead of a manufacturer making two goods, he considers a law firm producing two kinds of legal services, where the two services are distinguished by the fact that each is produced by a different lawyer. Nevertheless, the model would be the same. For each lawyer, there is a probability that low quality will be detected. If consumers punish both lawyers in a firm if they detect low quality by one lawyer, then low quality is likely to be punished more swiftly in a multi-member firm. This enables the multimember firm to credibly offer high quality at a lower quality-assuring price than either lawyer could offer if she practiced alone.

\section{Reputational Economics of Scale in a Finite-Horizon Model}

This section shows that reputational economies of scale exist also, under some circumstances, in a finite-horizon model similar to those pioneered by Kreps and Wilson (1982) 
and Milgrom and Roberts (1982). In this model, there are two types of firms, good and bad. Firms know their types, but consumers do not know firm types. Good firms always sell highquality goods, even if doing so is not profitable, while bad firms are opportunistic and sell high quality only if it maximizes the present discounted value of their profits. The literature sometimes calls good firms "commitment type" firms, while bad firms are "strategic type" firms. With probability $\theta$, a firm is good, and with probability $1-\theta$ a firm is bad. $0<\theta<1$. Assume that high quality goods $\operatorname{cost} c$ to produce, $0<c<1$, while low quality goods cost zero to produce. Consumers are willing to pay $v$ for high quality goods and zero for low quality goods. If consumers are uncertain about the quality of goods, the price they are willing to pay is proportional to the probability that they think quality will be high. So, if consumers think only good firms will sell high quality, and they cannot distinguish between good and bad firms, they are willing to pay $\theta v$. As in the main model, let $s(k)$ be the probability that consumers detect and punish low quality, where $k$ is the number of low quality units sold, $s(k)=0$, $\lim _{q \rightarrow \infty} s(q)=1, s^{\prime}>0$, and $s^{\prime \prime}<0$. Note that these assumptions imply that if a firm sells any low-quality goods, then $0<s<1$. There is only one firm. For simplicity, it is assumed that the firm sells either all high quality or all low quality, so $k=q \cdot{ }^{14}$ The firm sets the price, and consumers decide whether or not to buy. The discount factor is $\delta, 0<\delta<1$. Consumers know all parameters $-\theta, c, s, v$, and $\delta$ - but consumers do not know what type a firm is. For convenience, if the payoffs to high and low quality are the same, it is assumed that the bad firm sells high quality.

Consider first a one-period game. Obviously, the bad firm will sell low quality and the good firm will sell high quality. As a result, because the firm sets the price, the price will be $\theta v$.

Now consider the incentive-compatibility constraint of a bad firm in a two-period game. The bad firm will sell high quality at price $v$ if doing so maximizes the present discounted value of its profits. Assuming that consumers will believe it sells high quality in the first period (an assumption justified below), the bad firm will sell high quality if:

$$
v-c+\delta \theta v \geq v+\delta(1-s) \theta v
$$

The left side represents the bad firm's profits if it sells high quality in the first period and it is believed to sell high quality. It gets $v$ in the first period (the price consumers are willing to pay for high quality), and it pays $c$ to produce it. Because it sold high quality in the first period, consumers are willing to purchase from it in the second period. Nevertheless, because consumers

${ }^{14}$ No proof of the irrationality of mixing high and low quality is provided for this model, but there is no reason to think the proof in Appendix A would not, with appropriate modifications, apply to this model as well. As with the infinitely repeated model, the key is that the second derivative of $s(k)$ is negative. This means that the marginal cost of low quality (detection) is decreasing in quantity. Since the marginal benefit of low quality (cost savings) is constant with respect to quantity, if it is profitable to produce one unit of low quality, it is profitable to produce all low quality. 
know that the bad firm will sell low quality in the second (last) period, and since they do not know whether the firm is low quality, the price in the last period is $\theta v$, as in the one-period game. Since it costs the bad firm nothing to sell low quality, its discounted profits in the second period are $\delta \theta v$. If the bad firm sells low quality in the first period, it gets profits of $v$ (the price of high quality minus the costs of production, which are zero). Low quality is detected with probability $s$, and consumers rationally do not purchase from bad firms in the last period, so the present-discounted second-period profits are $\delta(1-s) \theta v$.

Rearranging the terms of expression (5), the bad firm sells high quality in the first period if $v \geq \frac{c}{\theta \delta s}$. That is, as long as $v$ is sufficiently high, high quality is rational. Note the effect of $s$. As $s$ goes up, the inequality is satisfied for a larger set of the parameter space. That is, the inequality is satisfied for lower values of $v, \theta$, and $\delta$ and for higher values of $c$. Since $s$ is an increasing function of quantity, $q$, and because the firm will set price equal to $v$, this means that, as under the infinitely repeated game model analyzed in prior sections, the lowest price consistent with the incentive compatibility constraint is lower for large firms than for small ones and thus there are there are reputational economies of scale.

Note also that quantity manifests itself in (5) only through $s$, the probability that bad quality in at least one product will be detected. If, as in the infinite-horizon model, bad quality was detected with certainty, $s=1$, quantity would be irrelevant. There would be no reputational economies of scale. A firm producing one good per period would behave in the same way as a firm producing a million goods per period, and a small firm would be just as trustworthy as a large one. As with the infinite-horizon model of reputation, the key to reputational economies of scale is the idea that poor quality is more likely to be detected and punished when quantity is high.

If the incentive-compatibility constraint (5) is satisfied, as in Kreps and Wilson's model, it is equilibrium behavior for bad firms to mimic good firms in the first period, and it is rational for consumers to believe that bad firms, under some parameters, sell high quality, except in the last period. More formally, it is a perfect Bayesian equilibrium for a bad firm to sell high quality in the first period for $v$ and for a bad firm to sell low quality in the last period for $\theta v$. In this equilibrium, consumers purchase goods for a price of $v$ in the first period, and purchase goods for $\theta v$ in the second period, unless a firm has been detected as having sold low quality in the first period, in which case consumers refuse to buy from the firm in the second period (or buy only at price zero). If consumers in the first period do not buy at the prices stated above, the firm does not sell in the second period. If firms sell at prices other than those stated above, consumers do not buy anything. Appropriate beliefs can be constructed to make these off-equilibrium-path behaviors rational.

We can now generalize to any number of periods. 
Proposition 4. There are reputational economies of scale in the finite-horizon model when low quality is detected with probability less than one, there is more than one period, and bad types either produce low quality in all periods or produce high quality in all but the last period.

Proof. The incentive-compatibility constraint for the two-period game is (5) above, and it has already been shown that it is satisfied for a lower price as quantity and thus $s$ increases. The key part of the incentive-compatibility constraint in the n-period game where $n \geq 2$ is:

$$
\sum_{i=0}^{i=n-2} \delta^{i}(v-c)+\delta^{n-1} \theta v \geq \sum_{i=0}^{i=n-2} \delta^{i}(1-s)^{i} v+\delta^{n-1}(1-s)^{n-1} \theta v
$$

Note, however, that satisfying inequality (6) is not sufficient to show that it is an equilibrium for a bad type to sell high quality in all but the last period. For that to be a perfect Bayesian equilibrium, it is necessary that the inequality also hold in periods less than $n$ but greater than 1. For example, if inequality (6) held for $n=3$ but inequality (5) did not for $n=2$, it would not be a sequentially rational equilibrium, and thus not a perfect Bayesian equilibrium, for a bad type to sell high quality in the second to last period of the three period game, so (6) would not be sufficient to show an equilibrium in which a bad type sold high quality in all but the last period. Fortunately, it is easy relatively easy to show that if inequality (5) is true, inequality (6) will be true for all $n \geq$ 2. As noted above, for the two-period game, inequality (5) is trues when $v \geq \frac{c}{\theta \delta s}$. If that same inequality holds, (6) will hold for $n \geq 2$. Proof by induction. We already know that the inequality holds for $n=2$. Denote the payoff from selling high quality in the first $a$ periods and low quality in the last $b$ periods as $\pi_{b}^{a}$. Using this notation, (6) can be rewritten as:

which can be rewritten as:

$$
(v-c)+\delta \pi_{1}^{n-2} \geq v+\delta(1-s) \pi_{n-1}^{0},
$$

$$
-c+\delta \pi_{1}^{n-2} \geq \delta \pi_{n-1}^{0}-s \delta \pi_{n-1}^{0} .
$$

By the inductive premise, we can assume $\pi_{1}^{n-2} \geq \delta \pi_{n-1}^{0}$, so it is sufficient to prove that when $v \geq \frac{c}{\theta \delta s},-c \geq-s \delta \pi_{n-1}^{0}$. The inequality to prove simplifies to $\pi_{n-1}^{0} \geq \frac{c}{s \delta}$. It is obvious from (6) that $\pi_{n-1}^{0} \geq v$. Note also that $\frac{c}{\theta \delta s} \geq \frac{c}{s \delta}$ because $0<\theta<1$. So $\pi_{n-1}^{0} \geq$ $\frac{c}{s \delta}$ whenever $v \geq \frac{c}{\theta \delta s}$. Thus, (6) is satisfied whenever $v \geq \frac{c}{\theta \delta s}$, which means the condition is satisfied for a larger set of the parameter space as $s$ and thus quantity increases. Q.E.D. ${ }^{15}$

${ }^{15}$ It is also noteworthy that expression (6) is also satisfied for a larger set of the parameter space as quantity and thus $s$ increases, but this is not important, because, as noted above, all that matters is that (6) will be satisfied whenever (5) is satisfied, and (5). The proof that expression (6) is also more likely to be satisfied as quantity follows simply from the fact that quantity appears only via $s$ and $s$ appears only on the right side of inequality (6). The derivative of the right side with respect to $s$ is negative. So, as $s$ 
Appendix 2 also considers equilibria in which the firm sells high quality in the first period, but switches to low quality before the last period. Reputational economies of scale do not generalize to such equilibria.

\section{Caveats, Extensions, and Diseconomies of Scale}

The models in this paper are, like all models, unrealistic in some respects. A key way in which these models are unrealistic is that they assume that if the firm chooses to sell with high quality, no low quality goods are sold. That is unrealistic, because even the best quality control cannot prevent production of an occasional defective product. Relaxing this assumption will reinforce the reputational advantage of larger firms because consumers can more easily discern whether defects are endemic or idiosyncratic when the firm sells a large number of goods. For example, if a firm sells ten goods and one is of poor quality, consumers cannot infer with confidence that the firm has bad quality control because it is possible that the one good of poor quality reflects simply bad luck from a firm that sells high quality goods with probability much higher than $90 \%$. On the other hand, if a firm sells one million goods and one hundred thousand are defective, the consumer can very reliably infer that the firm has poor quality controls that result in a high $(10 \%)$ rate of defects. ${ }^{16}$

An interesting extension of the analysis in this article applies to certification marks. Certification marks are a type of trademark in which one entity uses its reputation to back the idea that products sold by others meet certain quality standards (Holtzman 1991). Examples include marks such as Underwriter's Laboratory (for electrical safety) and the Union of Orthodox Rabbis (for kosher food). One puzzle is why certification is necessary. Why isn't the reputation of the company producing the goods sufficient to ensure quality? One possibility is that certification is helpful when the probably that low quality will be detected is very low. In that situation, the reputation of a single firm, even a large one, may not be sufficient to bond good behavior. The theory of umbrella branding set out in Section 5 is helpful here. Just as a firm producing two goods may be in a better position to bond the reputation of its products, so a certifier who certifies hundreds of goods may be in a better position to bond the reputation of all those products. If consumers blame the certifier when one of the certified firms is detected as shirking, then the certifier has an incentive to closely monitor all the firms it certifies, and consumers will rationally trust certified products more than uncertified. In this way, the effectiveness of certification is an application of the idea of reputational economies of scale. When the probability of detection is very low, the quantity sold by a single firm may not be sufficient to ensure high quality. Spreading the reputational umbrella of the certifier over the goods sold by multiple firms restores reputational incentives. This may explain why certification

goes up, inequality (6), is satisfied for a greater variant of parameters. Since the derivative of both leftand right-hand sides with respect to $v$ is positive, this means that inequality (6) is satisfied for lower values of $v$ as $s$ goes up. Since the derivative of $s$ with respect to $q$ is positive, this means that inequality (6) is satisfied for lower values of $v$ as quantity goes up

${ }^{16}$ The authors thank Steve Shavell for making the point in this paragraph. 
is especially prevalent for credence attributes, such as safety or kashrut, where even discerning consumers cannot tell whether the producer has shirked simply by consuming or experiencing the good (Dulleck, Kerschbamer and Sutter 2011). ${ }^{17}$

Although this paper suggests that larger firms are likely to be more trustworthy, that, of course, does not mean they never commit fraud or pass off low quality for high quality or engage in other misconduct. A key issue is the probability of detection. When misconduct is detected with low probability, even reputation may not be sufficient to incentivize good behavior. It is an advantage of the models in this paper that they explicitly take into account the probability of detection, whereas much of the previous literature assumed detection with certainty.

Another key requirement for reputational enforcement is that those affected by bad behavior punish the firm by refusing to deal with the firm in the future. While, as this paper shows, punishment can be part of an equilibrium, it is not the only one. If those affected by a firm's misbehavior believe that the firm will behave better in the future - perhaps because of a change in management or because of government regulation - then reputational constraints, and thus reputational economies of scale, are likely to fail (Macey 2013; Shapira \& Zingales 2017).

In addition, reputation models depend heavily on discount rates. If short-term gains are weighted more heavily than long-term ones, reputational constraints are much less likely to work. A key complication related to discount rates is whose discount rate matters in complex organizations. If managers tend to have short time horizons, while the firm and its shareholders value the long term, much will depend on agency costs and the extent to which firms are able to align managerial incentives with the long-term interest of the firm. In this regard, there may, in fact, be reputational diseconomies of scale. If larger firms have more difficulty aligning managerial interests with shareholder interests, reputational constraints may, in fact, be less binding on them. Or, if one looks at reputation from the perspective of the finite-horizon model, where there are good ("commitment") types and bad ("strategic") types, it is plausible to think that some individuals or small firms may be committed to good behavior, regardless of profit, but that seems implausible for larger organizations.

\section{Conclusion}

Relaxing the assumption that low quality is detected with certainty helps explain the widely presumed phenomenon of reputational economies of scale. If low quality is detected with probability less than one, reputational economies of scale emerge under the infinitely repeated game model of reputation, even in competitive markets. Similarly, if one drops the assumption that low quality is detected with certainty, reputational economies of scale also occur in a finitehorizon game model of reputation with two types where high quality is sold in all but the last

${ }^{17}$ Dan Klerman thanks Megan Stevenson for encouraging him to include this paragraph, which, in fact, motivated his interest in reputational economies of scale. 
period. Reputational economies of scale help explain many market phenomena, including gatekeeper liability, one-sided consumer contracts, umbrella branding, and the large size of firms in industries where product quality is hard to enforce through inspection or contract. 


\section{Appendix A. No Mixing of High and Low Quality}

The main text (and other articles in the literature) assume that a manufacturer that sells a single good sells either all high quality or all low quality of that good. Similarly, it is generally assumed that a manufacturer who sells two goods, A and B, sells uniform quality of A and uniform quality of B. That is, the text and literature assume that, although a firm may sell high quality $\mathrm{A}$ and low quality $\mathrm{B}$, or low quality $\mathrm{A}$ and high quality $\mathrm{B}$, the firm does not sell some high quality A and some low quality A and/or some high quality B and some low quality B. Given the assumption of fixed costs, $F$, that assumption may be reasonable. Perhaps producing some high and some low quality would require duplication of the fixed costs (or at least additional fixed costs). On the other hand, given the assumption that the marginal cost, $c$, is constant, no matter how many units are sold, it is also reasonable to consider the possibility that the manufacturer would choose to sell some high and some low-quality goods.

First consider the umbrella branding case, where there are two goods. To show that mixing is not rational, one must prove the following inequality:

$\frac{q_{A_{i}}\left(p_{A}^{\prime *}-c_{A}\right)+q_{B_{i}}\left(p_{B}^{\prime *}-c_{B}\right)}{r} \geq \frac{\left(q_{A_{i}}-k_{A_{i}}\right)\left(p_{A}^{\prime *}-c_{A}\right)+k_{A_{i}} p_{A}^{\prime *}+\left(q_{B_{i}}-k_{B}\right)\left(p_{B}^{\prime *}-c_{B}\right)+k_{B_{i}} p_{B}^{\prime *}}{r+s_{A B}\left(k_{A_{i}}, k_{B_{i}}\right)}$

Note that if $k_{A_{i}}=k_{B_{i}}=0$ that the left and right sides of the above expression would be equal. Note also that, given conditions $\mathrm{C} 1, \mathrm{C} 2$, and $\mathrm{C} 3$, if $k_{A_{i}}=q_{A_{i}}$ and/or $k_{B_{i}}=q_{B_{i}}$, the left and right sides of the above expression are either equal or the right side is smaller. The inequality can be rewritten as:

$$
0 \geq r\left(k_{A_{i}}+c_{A}+k_{B} c_{B}\right)-s_{A B}\left(k_{A_{i}}, k_{B_{i}}\right)\left[q_{A_{i}}\left(p_{A}^{\prime *}-c_{A}\right)+q_{B_{i}}\left(p_{B}^{\prime *}-c_{B}\right)\right]
$$

Like A1, the right and left sides of A2 are equal when $k_{A_{i}}=k_{B_{i}}=0$. Similarly, if $k_{A_{i}}=q_{A_{i}}$ and/or $k_{B_{i}}=q_{B_{i}}$, the left and right sides of the above expression are either equal or the right side is smaller. As a result, it is sufficient to prove that the second partial second derivatives of the right-hand side with respect to $k_{A_{i}}$ and $k_{B_{i}}$ are positive. Since the expressions are identical with respect to $k_{A_{i}}$ and $k_{B_{i}}$, it sufficient to prove the second derivative with respect to $k_{A_{i}}$ is positive. The second derivative with respect to $k_{A_{i}}$ is:

$$
-\frac{d^{2} s_{A B}}{d^{2} k_{A_{i}}}\left[q_{A_{i}}\left(p_{A}^{\prime *}-c_{A}\right)+q_{B_{i}}\left(p_{B}^{\prime *}-c_{B}\right)\right]
$$

Since the first term (the second derivative of $s_{A B}$ ) is negative, and the second term (in square brackets) is positive, the negative of the product of the two terms is positive. Q.E.D.

The one good case, where the manufacturer sells only one good, follows easily from the proof above. To prove that a firm would not sell some high and some low quality, just remove 
any terms with $B$ subscripts and then remove all the $A$ and $A B$ subscripts. The proof then follows in exactly the same way. 
Appendix B. Reputational Economies of Scale for Any Number of Periods in the Finite Horizon Game when the Bad Type produces low quality in the more than just the last period.

Consider a three-period game based on the model in Section 5. There are two cases to consider, where $c \leq \theta \delta s$, so the bad firm can be assumed to sell high quality in the second period if low quality is not detected in the first period, and where $v<\frac{c}{\theta \delta s}$ so the bad firm can be assumed to sell low quality in the second period. The situation where $v \geq \frac{c}{\theta \delta s}$ is considered in the main text. Consider the three-period game where $v<\frac{c}{\theta \delta s}$, that is, where the bad firm will sell low quality in the second and third periods. As in Kreps and Wilson's (1982) model, it is possible that the bad firm will sell high quality in the first period, even though it will sell low quality in later periods. Such an equilibrium would be plausible if the incentive-compatibility constraint is satisfied:

$$
v-c+\delta \theta v+\frac{\delta^{2}(1-s) \theta v}{1-\mathrm{s}(1-\theta)} \geq v+\delta(1-s) \theta v+\frac{\delta^{2}(1-s)^{2} \theta v}{1-\mathrm{s}(1-\theta)}
$$

As before, the left side is the payoff if the bad firm sells high quality in the first period, but not in any other period, whereas the right side is the payoff if the bad firm sells low quality in all periods. The last term of each side of (8) is slightly different than (6) because one must take into account the Bayesian inferences that consumers can draw from the fact that low quality has not been detected in the first two periods, under the assumption that consumers expect the firm to sell high quality in the first period and low quality in the second and third periods.

(8) simplifies to:

$$
v \geq \frac{c}{\delta \theta s\left[1+\frac{\delta(1-s)}{1-s(1-\theta)}\right]}
$$

If there are reputational economies of scale, the derivative of the right-hand side would always be negative, which means that the derivative of the denominator would be positive. The derivative of the denominator is:

$$
\delta \theta\left[1+\delta \frac{1-2 s+s^{2}(1-\theta)}{[1-s(1-\theta)]^{2}}\right]
$$

That is positive if:

$$
1+\delta-2 s[(1-\theta)+\delta]+s^{2}\left[(1-\theta)^{2}+\delta(1-\theta)\right]>0
$$

That expression, however, will be false when s and $\delta$ are close to one and $\theta$ takes intermediate values. For example, if $s=0.9, \delta=0.9$, and $\theta=0.5$, the left-hand side of (11) would be negative 0.053 , which would mean there would not be reputational economies of scale. Of course, for many parameters, expression (11) is true and there are reputational economies of 
scale, but such reputational economies of scale are not, as in the models examined in sections 25 , a general phenomenon. 


\section{References}

Bar-Isaac, Heski \& Steven Tadelis. 2008. Seller Reputation. Now Publishers.

Barnett, Jonathan M. (2012). Intermediaries Revisited: Is Efficient Certification Consistent with Profit Maximization? J. Corp. Law 37:475-527.

Bebchuk, Lucian A. \& Richard A. Posner. 2006. One-Sided Contracts in Competitive Consumer Markets. Mich. L. Rev. 104:827.

Becker, Gary S. 1968. Crime and Punishment: An Economic Approach. J. Pol. Econ. 76(2): 169-217.

Cai, Hongbin \& Ichiro Obara. 2009. Firm Reputation and Horizontal Integration. RAND J. Econ. 40:340-63.

Choi, Jay Pil. 1998. Brand Extension as Informational Leverage. Rev. Econ. Stud. 65:655-69.

Choi, Stephen. 1998. Market Lessons for Gatekeepers. Northwestern. U. L. Rev. 92:916.

Coffee Jr., John C. 2006. Gatekeepers: The Professions and Corporate Governance.

Oxford University Press.

Dulleck, Uwe, Rudolf Kerschbamer, \& Matthias Sutter. 2011. The Economics of

Credence Goods:An Experiment on the Role of Liability, Verifiability, Reputation and

Competition. Am. Econ. Review 101:526-55.

Holtzman, Terry E. 1991. Certification Marks: An Overview, Trademark Reporter 81:180-203.

Iacobucci, Edward. 2012. Reputational Economies of Scale, with Application to Law

Firms. 14 Am. Law \& Econ. Rev. 14:302-329.

Klein, Benjamin \& Keith Leffler. 1981. The Role of Market Forces in Assuring

Contractual Performance. J. of Pol. Econ. 89:615-641.

Kraakman, Reinier H. 1984. Corporate Liability Strategies and the Costs of Legal

Controls. Yale L. J. 93:857-898.

Kreps, David \& Robert Wilson. 1982. Reputation and Imperfect Information. J. Econ Theory 27:253-279.

MacLeod, W. Bentley. 2007. Reputations, Relationships and Contract Enforcement. J. Econ. Lit 45:595-628.

Macey, Johnathan R. 2013. The Death of Corporate Reputation: How Integrity Has Been Destroyed on Wall Street. Pearson Education.

Mailath, George J. \& Larry Samuelson. 2006. Repeated Games and Reputations: Long-

Run Relationships. Oxford University Press.

Milgrom, Paul \& John Roberts. 1982. Predation, Reputation and Entry Deterrence. J.

Econ. Theory 27:280-312.

Polinsky, A. Mitchell \& Steven Shavell. 2010. The Uneasy Case for Products Liability.

123 Harvard L. Rev. 123:1437-1492.

Rasmusen, Eric. 1989. A Simple Model of Product Quality with Elastic Demand. 29

Econ. Letters. 281-283.

Rasmusen, Eric. 2007. Games and Information. $4^{\text {th }}$ ed. Blackwell Publishing.

Rasmusen, Eric. 2016. Leveraging of Reputation through Umbrella Branding: The

Implications for Market Structure. J. Econ. \& Management 26:261-273.

Rasmusen, Eric \& Timothy Perri. 2001. Can High Prices Ensure Product Quality When

Buyers Do Not Know the Sellers' Cost? Econ. Inquiry 39:561-567. 
Robb, Rafael \& Arthur Fishman. 2005. Is Bigger Better? Customer Base Expansion through Word-of-Mouth Reputation. J. Pol. Econ. 113:1146-1162.

Rogerson, William. 1983. Reputation and Product Quality. Bell J. Econ 14:508-516. Shapira, Roy \& Luigi Zingales. 2017. Is Pollution Value-Maximizing? The DuPont Case. NBER Working Paper 23866.

Stigler, George J, 1970. The Optimum Enforcement of Laws. J. Pol. Econ. 73(3), 526536.

Wernerfelt, Birger. 1988. Umbrella Branding as a Signal of Product Quality: An Example of Signaling by Posting a Bond. RAND J. Econ 19:458-466. 